\title{
Planning Solid Waste Collection with Robust Optimization: Location-Allocation, Receptacle Type, and Service Frequency
}

\author{
Maryam Nikouei Mehr' ${ }^{1}$ and Ronald G. McGarvey ${ }^{1,2}$ \\ ${ }^{1}$ Department of Industrial and Manufacturing Systems Engineering, University of Missouri, Columbia, MO 65211, USA \\ ${ }^{2}$ Harry S. Truman School of Public Affairs, University of Missouri, Columbia, MO 65211, USA \\ Correspondence should be addressed to Ronald G. McGarvey; mcgarveyr@missouri.edu
}

Received 8 August 2016; Revised 22 November 2016; Accepted 7 December 2016; Published 29 January 2017

Academic Editor: Mhand Hifi

Copyright ( 2017 Maryam Nikouei Mehr and Ronald G. McGarvey. This is an open access article distributed under the Creative Commons Attribution License, which permits unrestricted use, distribution, and reproduction in any medium, provided the original work is properly cited.

\begin{abstract}
Consider the problem faced by a purchaser of solid waste management services, who needs to identify waste collection points, the assignment of waste generation points to waste collection points, and the type and number of receptacles utilized at each collection point. Receptacles whose collection schedule is specified in advance are charged a fixed fee according to the number of times the receptacle is serviced (emptied) per week. For other receptacles, the purchaser pays a fee comprised of a fixed service charge, plus a variable cost that is assessed on a per-ton-removed basis. We develop a mathematical programming model to minimize the costs that the purchaser pays to the waste management provider, subject to a level of service that is sufficient to collect all of the purchaser's required waste. Examining historical data from the University of Missouri, we observed significant variability in the amount of waste serviced for nonscheduled receptacles. Because this variability has a significant impact on cost, we modified our model using robust optimization techniques to address the observed uncertainty. Our model's highly robust solution, while slightly more expensive than the nonrobust solution in the most-optimistic scenario, significantly outperforms the nonrobust solution for all other potential scenarios.
\end{abstract}

\section{Introduction}

Municipal solid waste management (SWM) refers to the management of the waste that is generated as a result of residential, institutional, and commercial activities [1]. This research was motivated by a project with University of Missouri (MU) Sustainability Office, regarding its SWM contract with the local municipality, the city of Columbia, MO. Circa 2014, the university was paying the city approximately $\$ 410,000$ annually to collect solid waste from campus locations. MU was concerned that it was potentially paying more than necessary, due to what was perceived as a large number of waste collection points. An additional complication was that the city's contract terms varied with respect to the type of receptacle used at each collection point. Dumpsters were charged on a frequency of service basis, without regard to the weight of the waste in the dumpster, with the service dates specified a priori by the customer (e.g., service every Monday and Thursday). Compactors and roll-off containers were charged on a weight and service charge basis, with the service dates not necessarily specified in advance, but instead potentially arranged for on an as-needed basis.

An analysis aiming to identify a minimum-cost strategy for the university would thus need to address the following decisions:

(a) Where should the waste collection points be located?

(b) For each campus building, at which waste collection point should its waste be assigned? Note that MU employees are responsible for moving waste to each waste collection point; these efforts (and their associated costs) are not included in the university's contract with the city.

(c) What type(s) of receptacles should be sited at each waste collection point?

(d) For each dumpster, what should be its frequency of service? 
Decisions (a) and (b) are common to any general locationallocation problem. Decision (c) is consistent with locationallocation models that differentiate between types of candidate facilities.

Decision (d), however, is not typical for such optimization models. Clearly, the number of services required per week is related to the amount of waste expected to be assigned to a location and the capacity of the receptacles placed at that site. It is not sufficient, though, to simply identify the number of services per week for a dumpster, the university must also identify the specific days on which service will occur for each dumpster, which greatly complicates the modeling, since demands accumulate over time in the absence of service, and these demands must be allocated the first service day occurring after demand generation.

1.1. Test Case for Application. The University of Missouri is the largest educational institution in Missouri. There are several thousand faculty, staff, and students working and studying on the campus daily. The university has a contract with the city of Columbia, who provides solid waste management services to the university. The city provides receptacles, along with the labor and equipment necessary to collect material from receptacles, and transports the collected material (both waste and recyclables) to the city solid waste management facility. Because the city did not charge the university for servicing recyclable materials, we exclude such receptacles from our analysis.

At the time of this research, there were 171 city-serviced waste receptacles distributed across 111 buildings around the main campus area. Figure 1 shows the distribution of receptacles over these 111 locations. For our analysis, we will consider these 111 buildings as waste generation points. Each of these 111 buildings will also be considered as a potential waste collection point.

There are three primary types of city-provided receptacles in use on campus: dumpsters, roll-off containers, and compactors. Each receptacle type is available in multiple sizes. For example, dumpsters are available in 2-, 4-, 6-, and 8-cubic yard capacities.

In order to identify the required level of service, we need to know the amount of solid waste generated each day at each of these 111 points. Unfortunately, MU does not maintain data recording how much waste is generated each day at each building. For waste that is serviced by dumpsters, MU does not obtain any data regarding the weight of the waste that is serviced. The most-recent data available came from an internal 2003 study on the university's dumpster utilization. In this study, students visually observed dumpsters around campus to estimate what percentage of their capacity had been used each day for one week. This 2003 study categorized university buildings into 10 groups: academic, administrative, apartments, residence halls, dining halls, medical, parking garages, recreation and athletics, research, and support buildings. Since the number of buildings and dumpsters on the campus has changed since this 2003 study was performed, we computed the average dumpster percent utilization for each building category for each day of the week and applied the relevant factor to all dumpsters, generating an estimate of the volume of generated waste for each day of the week for each dumpster.

For waste serviced by compactors and roll-offs, MU was able to provide data regarding the total weight of waste serviced at each receptacle for the period covering January 2012 through June 2013. However, these data do not present details on differences in waste generation across different days of the week. We thus took the daily variations around the average computed above for dumpsters and applied this variability to compactors and roll-offs (maintaining the correct overall total weight for compactors and roll-offs) to generate estimates of waste generation for each day of the week for buildings serviced by compactors and roll-offs. We translated these weights into volumes by assuming a rate of 20 cubic yards of (noncompacted) waste per ton.

We were now able to estimate the volume of waste generated in all buildings around campus per day of the week, as demonstrated in Figure 2. Because service is not available on Saturday or Sunday, the waste generated on these days is treated as being generated on Monday, explaining why Monday has the largest total waste generation estimate across all days of the week.

The remainder of this paper is organized as follows. Section 2 presents a review of operations research literature related to SWM. Section 3 provides details of our basic modeling formulation, assuming no variability in the system. In Section 4, we present an application of our model to data from MU. Due to the variability observed in the MU data, we extended our basic model using a robust optimization (RO) approach; these modeling extensions and computational results are also presented in Section 4. Finally, conclusions and directions for potential future study are discussed in Section 5 .

\section{Literature Review}

Solid waste management deals with the organized handling of waste material from generation sources through the recovery processes to disposal [2]. SWM is known to be a complicated and costly procedure for urban areas. According to Shamshiry et al. [3] the majority of of SWM costs (approximately 75\%) are due to the waste collection process. Most of the operations research literature related to SWM has addressed the problem from the perspective of a cost-benefit analysis [4], in which the decision-maker attempts to measure all of the positive and negative effects of each decision in a scenario relative to a common measurement, such as dollars.

Operations research models have been extensively used to address regional planning decisions such as the selection of collection site locations $[5,6]$, transfer station locations [7-12], waste processing facility locations [12-16], and landfill location $[7,10,13,15]$. Such analyses typically aim to identify the best locations for sites while minimizing cost.

Operational decisions for SWM have also been examined with operations research tools. Collection patterns for routing and scheduling trucks to collect waste around cities, accounting for the time needed to collect waste as well as the selection of collection days, are discussed in Ghiani et al. $[17,18]$ and Ghose et al. [19]. Districting decisions, in which 

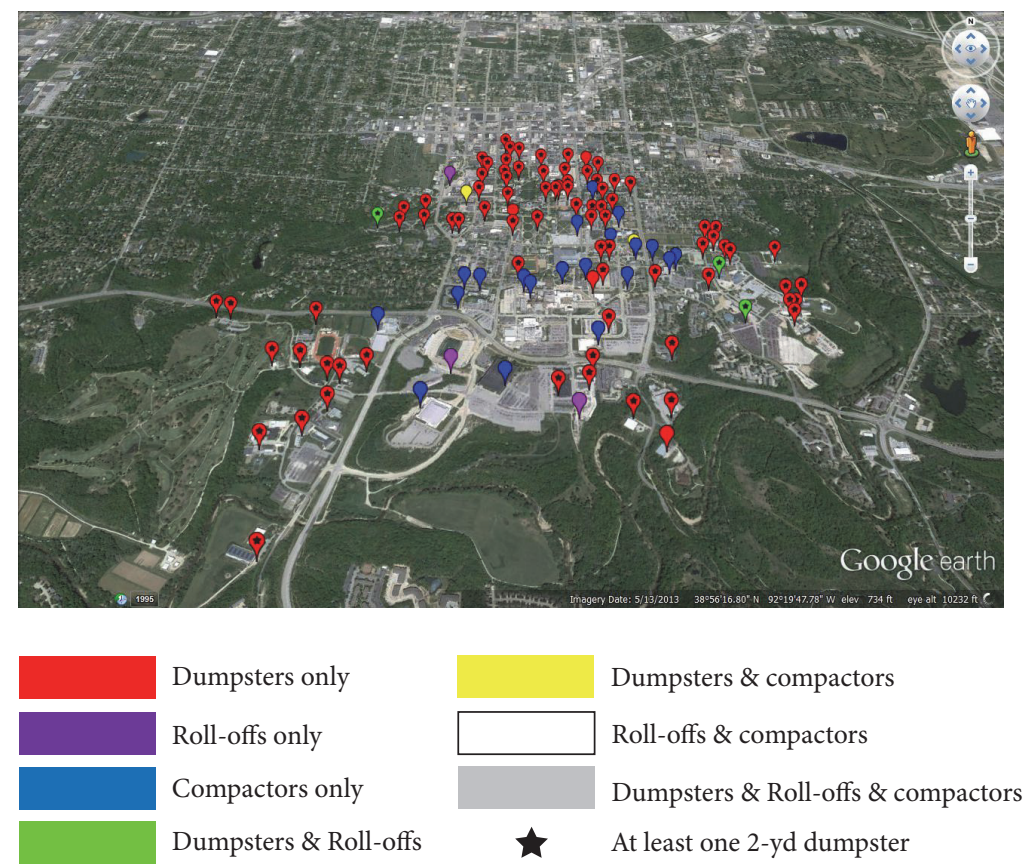

FIGURE 1: Distribution of receptacles around campus.

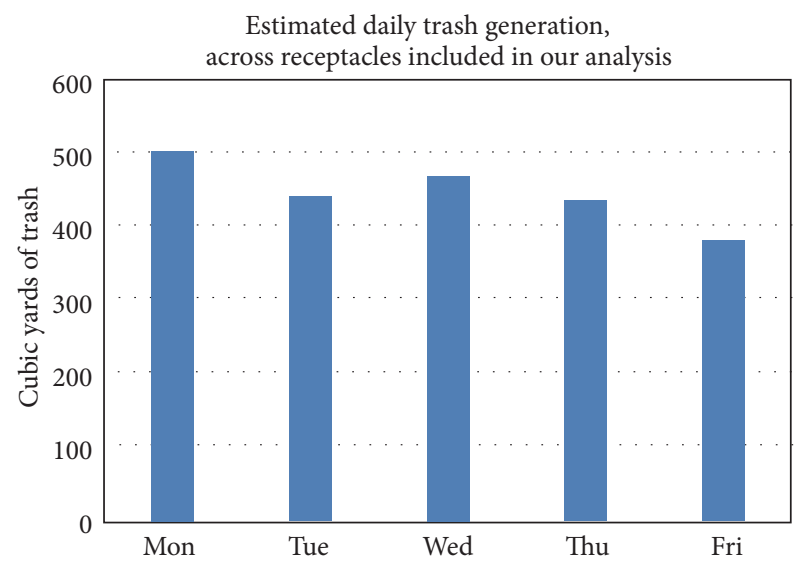

FIGURE 2: Total waste generation across campus, per day of the week.

the region to be served is divided into zones such that the total waste flow in each zone is less than the capacity of the trucks serving it, are presented in Ghiani et al. [17, 18] and Hanafi et al. [20]. One previous study which considered frequency of service was Katragjini et al. [21], although this paper only considered a fixed set of collection locations, with receptacles of fixed size, and required that all potential collection timetables be identified a priori.

The studies mentioned previously generally model municipal SWM problems using deterministic mathematical programming techniques. A number of authors have also examined these issues with optimization models that address uncertainty. Fuzzy mathematical programming has been used by a number of authors to examine SWM decisions [2226]. Li [27] examined SWM under uncertainty using an inexact mathematical programming framework, in which uncertain parameters are expressed as intervals with known lower and upper bounds, but unknown distributions. However, approaches for identifying solutions that provide a performance guarantee in the event of uncertainty, such as robust optimization [28], do not appear in the literature for solid waste management applications.

\section{Problem Description}

Consider an entity that purchases SWM services from a waste management provider. The purchaser needs to identify the locations at which waste will be collected, along with the type and number of receptacles to be placed at each waste collection point. Suppose that there are two basic types of receptacles (with a variety of possible sizes and capacities for each type): dumpsters and compactors. From the purchaser's perspective, the primary difference between these receptacle types pertains to the tariff structure. The purchaser pays a fixed fee according to the number of times the dumpster is serviced (emptied) each week, with a minimum of one and a maximum of five services per week for any utilized dumpster. This frequency of service must be specified at the outset of the contract. For a compactor, there is no predetermined servicing schedule. However, when a compactor is serviced, the purchaser pays a fee comprised of a fixed service charge, plus a variable cost that is assessed on a per-ton-removed basis.

Another set of decisions that the purchaser needs to make, but which need not be communicated to the waste 
management provider, are the assignment of waste generation points (assumed here to be buildings) to waste collection points. Should transportation be necessary between a waste generation point and a waste collection point; this transportation will be performed by the SWM purchaser and is not a responsibility of the waste management provider.

We assume that the purchaser wishes to minimize the costs paid to the waste management provider, subject to a level of service that is sufficient to collect all of the purchaser's required waste. We further assume that the amount of waste generated on each day at each waste generation point is known. Finally, assume that compactors will be serviced when they reach their maximum capacity (and not according to a predetermined schedule).

Our mathematical model is as follows.

Sets

\section{$\mathscr{I}:$ waste generation points.}

$\mathscr{J}$ : candidate waste collection points.

$\mathscr{K}:$ receptacle types.

$\mathscr{C} \subset \mathscr{K}$ : compactor types (roll-off receptacles are included in this subset).

$\mathscr{U} \subset \mathscr{K}:$ dumpster types.

$\mathscr{D}$ : days of week, $\mathscr{D}=\{$ Mon, Tue, Wed, Thu, Fri $\}$.

$\mathscr{F}$ : frequency of service per week $\mathscr{F}=\left\{f_{1}, f_{2}, f_{3}\right.$, $\left.f_{4}, f_{5}\right\}$.

\section{Parameters}

$\theta_{u f}$ : incremental cost, per month, for receiving service $f$ times per week (beyond cost for receiving service $(f-1)$ times per week) for dumpster of type $u$.

$\Pi_{C}$ : fixed cost per service for compactor of type $c$.

$\Phi_{c}$ : variable cost per ton of waste received from compactor of type $c$.

$\psi$ : cubic yards per ton of waste.

$\alpha_{i d}$ : volume of waste generated at location $i$ on day $d$.

$\beta_{k}$ : capacity volume of receptacle type $k$.

$\gamma_{k}$ : area required at collection point per receptacle of type $k$.

$\epsilon_{j}$ : area available for receptacles at collection point $j$.

$\Delta_{i j}$ : distance between generation point $i$ and collection point $j$.

$\Omega_{C}$ : annual depreciation fee (paid by purchaser) per compactor of type $c$.

$M$ : arbitrarily large "big $M$ ” value.

\section{Decision Variables}

$w_{i j}=\{1$, if waste generated at point $i$ is collected at point $j$; 0 , otherwise $\}$.

$y_{j d}=\{1$, if dumpsters at collection point $j$ are serviced on day $d ; 0$, otherwise $\}$. $p_{j f}=\{1$, if dumpsters at collection point $j$ are serviced at least $f$ times per week; 0 , otherwise\}.

$v_{i j d}$ : volume of waste generated at point $i$ on day $d$ that is assigned to compactors at collection point $j$.

$r_{j c d}$ : volume of waste generated on day $d$ that is assigned to compactors of type $c$ at collection point $j$.

$z_{i j d_{1} d_{2}}$ : volume of waste generated at point $i$ on day $d_{1}$ that is assigned to a dumpster at collection point $j$ and serviced on day $d_{2}$.

$a_{\text {jud }}$ : volume of waste assigned to dumpsters of type $u$ at collection point $j$ that are serviced on day $d$.

$x_{j u f}$ : number of dumpsters at collection point $j$ that are serviced at least $f$ times per week.

$q_{j k}$ : number of receptacles of type $k$ at collection point $j$.

\section{Objective Function}

$$
\begin{aligned}
\min & 12 \sum_{j} \sum_{u} \sum_{f} x_{j u f} \theta_{u f} \\
& +52 \sum_{j} \sum_{c} \sum_{d}\left(\Pi_{C} \frac{r_{j c d}}{\beta_{c}}+\Phi_{c} \frac{r_{j c d}}{\psi}\right)+\sum_{j} \sum_{c} q_{j c} \Omega_{c} .
\end{aligned}
$$

\section{Constraints}

$$
\begin{aligned}
& \sum_{j} w_{i j}=1 \quad \forall i \in \mathscr{I} \\
& \sum_{d_{2}} z_{i j d_{1} d_{2}}+v_{i j d_{1}}=\alpha_{i d_{1}} w_{i j} \quad \forall i \in \mathscr{I}, j \in \mathscr{J}, d_{1} \in \mathscr{D} \\
& \sum_{i} v_{i j d}=\sum_{c} r_{j c d} \quad \forall j \in \mathscr{J}, d \in \mathscr{D} \\
& \sum_{i} \sum_{d_{1}} z_{i j d_{1} d_{2}}=\sum_{u} a_{j u d_{2}} \quad \forall j \in \mathscr{J}, d_{2} \in \mathscr{D} \\
& a_{j u d} \leq \beta_{u} q_{j u} \quad \forall j \in \mathscr{J}, u \in \mathscr{U}, d \in \mathscr{D} \\
& \sum_{k} \gamma_{k} q_{j k} \leq \epsilon_{j} \quad \forall j \in \mathscr{J} \\
& \sum_{u} a_{j u d} \leq M y_{j d} \quad \forall j \in \mathscr{J}, d \in \mathscr{D} \\
& z_{i j d d} \geq \alpha_{i d} y_{j d}-v_{i j d}+M\left(w_{i j}-1\right) \\
& \forall i \in \mathscr{I}, j \in \mathscr{J}, d \in \mathscr{D} \\
& z_{i j d d}+z_{i j d(d+1)} \geq \alpha_{i d} y_{j(d+1)}-v_{i j d}+M\left(w_{i j}-1\right) \\
& \forall i \in \mathscr{I}, j \in \mathscr{J}, d \in \mathscr{D} \\
& z_{i j d d}+z_{i j d(d+1)}+z_{i j d(d+2)} \geq \alpha_{i d} y_{j(d+2)}-v_{i j d} \\
& +M\left(w_{i j}-1\right) \quad \forall i \in \mathscr{I}, j \in \mathscr{J}, d \in \mathscr{D}
\end{aligned}
$$




$$
\begin{aligned}
& z_{i j d d}+z_{i j d(d+1)}+z_{i j d(d+2)}+z_{i j d(d+3)} \geq \alpha_{i d} y_{j(d+3)} \\
& -v_{i j d}+M\left(w_{i j}-1\right) \quad \forall i \in \mathscr{I}, j \in \mathscr{J}, d \in \mathscr{D} \\
& \sum_{f} p_{j f}=\sum_{d} y_{j d} \quad \forall j \in \mathscr{J} \\
& p_{j f_{2}} \leq p_{j f_{1}} \quad \forall j \in \mathscr{J} \\
& p_{j f_{3}} \leq p_{j f_{2}} \quad \forall j \in \mathcal{J} \\
& p_{j f_{4}} \leq p_{j f_{3}} \quad \forall j \in \mathcal{J} \\
& p_{j f_{5}} \leq p_{j f_{4}} \quad \forall j \in \mathscr{J} \\
& x_{j u f} \geq q_{j u}+M\left(p_{j f}-1\right) \quad \forall j \in \mathscr{J}, u \in \mathcal{U}, f \in \mathscr{F} \\
& r_{j c d} \leq \beta_{c} q_{j c} \quad \forall j \in \mathscr{J}, c \in \mathscr{C}, d \in \mathscr{D} \\
& \sum_{i} w_{i j} \leq M w_{j j} \quad \forall j \in \mathscr{J} \\
& \sum_{k} q_{j k} \leq M \sum_{i} w_{i j} \quad \forall j \in \mathscr{J}, u \in \mathscr{U}, f \in \mathscr{F} \\
& v_{i j d}, r_{j c d}, z_{i j d_{1} d_{2}}, a_{j u d} \geq 0 \\
& \forall i \in \mathscr{I}, j \in \mathscr{J}, c \in \mathscr{C}, u \in \mathcal{U} ; d, d_{1}, d_{2} \in \mathscr{D} \\
& q_{j k}, x_{j u f} \geq 0 \text {; integer } \\
& \forall j \in \mathscr{J}, k \in \mathscr{K}, u \in \mathscr{U}, f \in \mathscr{F} \\
& w_{i j}, y_{j d}, p_{j f} \text { binary }
\end{aligned}
$$$$
\forall i \in \mathscr{I}, j \in \mathscr{J}, d \in \mathscr{D}, f \in \mathscr{F} .
$$

Objective function (1) minimizes the purchaser's total annual cost. The objective's first term computes the collection costs for dumpsters (multiplied by 12 , since this is a monthly cost), the second term calculates the collection cost for compactors (comprised of both a per-service charge and a perton charge; multiplied by 52 , since this is a weekly cost), and the third term determines the depreciation cost for compactors.

Constraint (2) ensures that all waste generated at point $i$ is collected at exactly one location $j$. Constraint (3) requires that the total waste generated at point $i$ on day $d_{1}$ be assigned to a combination of dumpsters and compactors at point is assigned collection point $j$. Constraint (4) distributes the total waste allocated to compactors at collection point $j$ on day $d$ across different compactor types. Constraint (5) similarly distributes the total waste allocated to dumpsters at collection point $j$ that will be serviced on day $d_{2}$ across different dumpster types. In constraint (6), we ensure that the volume of waste assigned to be serviced on day $d_{2}$ across each dumpster type at collection point $j$ does not exceed the available capacity. Constraint (7) constrains the total area consumed by waste receptacles at collection site $j$ to not exceed the available space. Constraint (8) is used to activate the binary variable $y_{j d}$ that indicates if dumpsters at collection point $j$ are serviced on day $d$.

The primary new contribution of this model is contained in the constraints that relate frequency of service to capacity. Consider, for example, a case in which four cubic yards of waste are generated on each weekday and assigned to a 10cubic yard capacity dumpster. A collection schedule with two services per week would be sufficient to accommodate all waste on average but would not have sufficient capacity on each day (e.g., if collection were scheduled on Tuesday and Friday, 12 cubic yards of waste would have accumulated between the collection on Tuesday and the collection on Friday, violating the dumpster's capacity). To avoid this problem, we need to relate the day that dumpster-serviced waste is generated to the first-scheduled service date following generation. This is accomplished via constraints (9), (10), (11), and (12). First, note that if $w_{i j}=0$ and generation point $i$ does not assign its waste collection point $j$, then the constraint is automatically satisfied.

For cases when $w_{i j}=1$, observe that constraints (5) and (8) together ensure that if $y_{j d_{2}}=0$ for waste service day $d_{2}$, then $z_{i j d_{1} d_{2}}=0$ for each waste generation day $d_{1}$. Now, for any day $d$ that receives waste service (i.e., $y_{j d}=1$ ), constraint (9) requires that all of the waste generated on day $d$ must receive service on the same day $d$ (i.e., $z_{i j d d}$ is equal to the total amount of dumpster-assigned waste generated at point $i$ on day $d$ ). If, instead, there is no dumpster service at collection point $j$ on day $d$, with the first service after day $d$ occurring on day $d+n$, then the following conditions must be true: (a) $y_{j d}=y_{j(d+1)}=\cdots=y_{j(d+n-1)}=0$, implying that $z_{i j d d}=$ $z_{i j d(d+1)}=\cdots=z_{i j d(d+n-1)}=0$; (b) $y_{j(d+n)}=1$, implying that $z_{i j d(d+n)}$ is equal to the total amount of dumpster-assigned waste generated at point $i$ on day $d$. Note that $z_{i j d(d+h)}=0$ where $h>n$, since the total amount of dumpster-assigned waste generated on day $d$ has already been assigned to collection day $d+n$.

To compute the cost associated with dumpsters, we next need to identify the number of services per week. Constraints (13), (14), (15), (16), and (17) are linear constraints used to model dumpster collection costs through use of a piecewiselinear representation by computing the number of weekly services for dumpsters at collection point $j$ based upon the total number of days receiving dumpster service at this point. Constraint (18) then ensures that all type $u$ dumpsters at collection point $j$ are charged for service based on this number of weekly dumpster services at collection point $j$. Constraint (19) ensures that the volume of waste assigned to compactors of type $c$ at collection point $j$ on day $d$ does not exceed the available capacity. Constraint (20) permits collection point $j$ to service other generation points only if $j$ services its own waste. Constraint (21) permits receptacles to be placed at collection point $j$ only if collection point $j$ services at least one waste generation point. Finally, constraints (22), (23), and (24) define the appropriate variables as nonnegative, integeronly, and binary variables, respectively.

Observe that this model includes both strategic (location) and tactical (scheduling) decisions, while such a purview is 
TABLE 1: Monthly dumpster service cost based on capacity and frequency of service.

\begin{tabular}{|c|c|c|c|c|c|}
\hline Services per week & 1 & 2 & 3 & 4 & 5 \\
\hline 2 cubic yards & $\$ 60.55$ & $\$ 77.85$ & $\$ 95.16$ & $\$ 112.46$ & $\$ 129.77$ \\
\hline 4 cubic yards & $\$ 73.25$ & $\$ 107.86$ & $\$ 142.47$ & $\$ 177.08$ & $\$ 211.69$ \\
\hline 6 cubic yards & $\$ 88.72$ & $\$ 140.63$ & $\$ 192.55$ & $\$ 244.45$ & $\$ 296.37$ \\
\hline 8 cubic yards & $\$ 103.26$ & $\$ 172.48$ & $\$ 241.69$ & $\$ 310.91$ & $\$ 380.00$ \\
\hline
\end{tabular}

TABle 2: Distribution of dumpsters on MU campus.

\begin{tabular}{ccccc}
\hline \multirow{2}{*}{ Dumpsters } & 2-yard & 4-yard & 6 -yard & 8 -yard \\
& 132 & 1 & 3 & 4 \\
\hline
\end{tabular}

not typically included in operations research models, as noted by Rappold and Van Roo [29]:

\begin{abstract}
Due to the interdependent nature of these strategic and tactical considerations, it is imperative to include the tactical consequences explicitly in the strategic decision-making process. Unfortunately, in practice, this seems more often an exception rather than the rule.
\end{abstract}

Due to the efficiency of the formulation and the relatively small problem size, both sets of considerations can be simultaneously optimized by our model. Moreover, in the application to be presented in Section 4, the purchaser must specify both the locations and the schedule of collections when the contract is developed with the waste management provider.

\section{Application and Computational Results}

As discussed previously, the city's tariff structure for dumpsters is different from the charges imposed for servicing rolloffs and compactors. Consider the city's tariff structure for dumpsters, as presented in Table 1. These costs are based solely on the dumpster capacity and frequency of weekly service. The cost does not vary as a function of the amount of waste collected when a dumpster is serviced. For each dumpster that is utilized, the university must specify in advance on which days that dumpster will receive service (service is available on weekdays, Monday through Friday).

The bill received from the city shows MU is charged for 142 dumpsters, 140 of which are located in the main campus area and thus included in our analysis. Table 2 shows the number of dumpsters in the university's contract in the main campus area. The total charge associated with these 140 dumpsters over the one-year interval May 2013 to April 2014 was $\$ 189,120$.

Compactors and roll-offs are charged in a very different way than are dumpsters. Compactors and roll-offs are billed based on (a) tonnage fee at a rate of $\$ 34.96$ per ton, (b) number of times the receptacle is serviced ("pulled"), and (c) depreciation fee, applied to compactors only, which we estimated as $\$ 465$ per compactor per year. The pull fee varies based on the receptacle's size. For small (14 and 15 cubic yards) compactors and roll-offs, the university is charged $\$ 50.93$ per pull. For larger, "full-size" compactors and roll-offs, the fee is 71.64 per pull.

There were 22 compactors and 9 roll-offs located in the main campus area; four of these compactors and one of these roll-offs were small-sized (14- or 15-cubic yard capacity). To compute the university's costs associated with this set of compactors and roll-offs, one needs to know the tonnage and number of pulls for these 31 receptacles. We used the January 2012 through June 2013 dataset discussed above to estimate the amount of waste generated at this set of receptacles as follows:

(i) 3,899 compactor and roll-off tons, at a total cost of $\$ 136,326$.

(ii) 127 small compactor and roll-off pulls, at a total cost of $\$ 6,486$.

(iii) 948 full-size compactor and roll-off pulls, at a total cost of $\$ 67,929$.

(iv) Depreciation fee on compactors, at a total cost of $\$ 10,246$.

Our total estimated cost across the 31 compactors and roll-offs located in the main campus is thus equal to $\$ 220,986$. Adding this to the dumpster charge mentioned previously, we estimate that across the year spanning May 2013 to April 2014, the university's solid waste disposal bill across all receptacles in the main campus area was $\$ 410,106$; we will utilize this estimate as the baseline cost for the analysis to follow.

4.1. Modeling Assumptions. We will utilize the optimization model presented in Section 3 to identify alternative waste collection decisions that would minimize the charges paid by the university to the city for SWM services. In order to apply this model, we make the following set of assumptions.

For each candidate waste collection point, we identified the existing space currently utilized for waste receptacles and assumed that this was the only space potentially available for receptacle siting. We did not account for differences in receptacle types when identifying the available space at potential waste collection points; our approach would allow a location that is currently used for dumpsters to potentially be utilized for compactor siting, if there is sufficient existing space.

For dumpsters, the assigned waste that accumulates between scheduled services cannot exceed the dumpster's nominal capacity. Modeling capacity for compactors and rolloffs is more difficult, however, since these receptacle types are not serviced according to a prearranged schedule but are intended to be serviced when the compactor or roll-off is near its storage capacity. While MU did not have historical data 


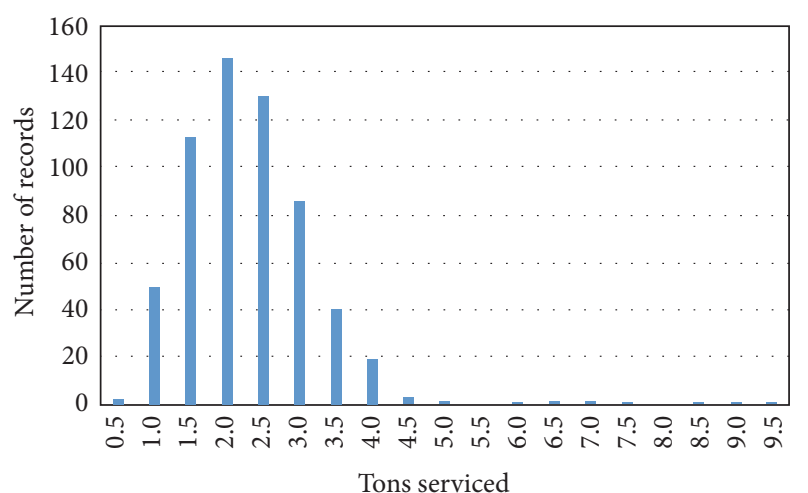

FIGURE 3: Variability in weight per service for 30-yard roll-offs.

recording the volume at which compactors or roll-offs were serviced, data were available presenting the weight pulled at each compactor and roll-off servicing. These historical data demonstrated significant variation in the weights at which individual compactors or roll-offs were serviced. Figure 3 shows the variability in the weight of waste pulled per service for all 30-yard roll-off containers.

Consider for a moment the implication of this variability. Because the fee for compactors and roll-offs varies as a function of the number of services and the weight serviced, variability in the weight per service will impact the university's overall cost, even if we assume that the amount of waste being generated is known and deterministic. In such a case, the tonnage cost associated with the weight of waste serviced by compactors and roll-offs would be fixed, independent of the number of such receptacles that are utilized. However, even for a fixed set of compactors and roll-offs, the number of services could vary greatly with variations in the weight per service, leading to considerable uncertainty in the total cost. To accommodate this uncertainty we modified our optimization model using a robust optimization approach

4.2. Robust Optimization Model. Robust optimization (RO), as developed by Ben-Tal and Nemirovski, [28], is another approach for optimizing under uncertainty. Instead of considering probabilistic information to protect the solution against uncertainty, RO models construct a solution that is feasible for any realization of the uncertainty in a given set. Bertsimas and Sim [30] later extended these RO concepts to linear models with integer variables. Gabrel et al. [31] provided a survey of $130 \mathrm{RO}$ papers appearing in the operations research literature; none of these papers addressed waste management issues. Accordingly, this research aims to extend RO concepts to SWM planning problems, with a focus on the location-allocation and frequency of service decisions facing a purchaser of SWM services. follows.

The RO modifications to our previous model appear as

\section{Parameters}

$\eta$ : protection level in the objective function.

$g_{c}$ : midpoint of waste capacity per service for compactor type $c$. $b_{c}$ : cost increase associated with maximum-allowable deviation from midpoint for waste capacity per service for compactor type $c$.

\section{Decision Variables}

$s$ : robust variable associated with protection level.

$t_{j c d}$ : robust variable identifying cost increase above protection level for waste generated on day $d$ that is assigned to compactors of type $c$ at collection point $j$. $\ell_{j c d}$ : robust variable identifying absolute value of volume of waste generated on day $d$ that is assigned to compactors of type $c$ at collection point $j$.

\section{Objective Function}

$$
\begin{aligned}
\min & 12 \sum_{j} \sum_{u} \sum_{f} x_{j u f} \theta_{u f} \\
& +52 \sum_{j} \sum_{c} \sum_{d}\left(\Pi_{C} \frac{r_{j c d}}{g_{c}}+\Phi_{c} \frac{r_{j c d}}{\psi}\right) \\
& +\sum_{j} \sum_{c} q_{j c} \Omega_{c}+s \eta+\sum_{j} \sum_{c} \sum_{d} t_{j c d} .
\end{aligned}
$$

\section{Constraints}

$$
\begin{aligned}
s+t_{j c d} & \geq b_{c} \ell_{j c d} \quad \forall j \in \mathscr{J}, c \in \mathscr{C}, d \in \mathscr{D} \\
-\ell_{j c d} & \leq r_{j c d} \leq \ell_{j c d} \quad \forall j \in \mathscr{J}, c \in \mathscr{C}, d \in \mathscr{D} .
\end{aligned}
$$

In this robust optimization model, objective (25) replaces objective (1) in the previous model. Parameters $g_{c}$ and $b_{c}$ are identified based on the variability observed in the weight pulled per compactor or roll-off servicing. As an example, consider 30-yard roll-off containers. As presented in Figure 3, the preponderance of services ( 98 percent) occurred with pull weights between 0.5 and 4.5 tons. For this receptacle type, we assumed that midpoint pull capacity $g_{c}$ was equal to 2.5 tons, with the maximum-allowable deviation from this midpoint, denoted by $\widehat{g}_{c}$, equal to 2 tons (generating an allowable range of 0.5 to 4.5 tons per pull). Parameter $b_{c}$, identifying the cost increase associated with this maximum-allowable deviation from midpoint $g_{c}$ per unit waste $r_{j c d}$, can then be computed as the increase in pull cost times the number of increased services under the worst-case (minimum-allowable servicing weight) scenario, where

$$
b_{c}=52 * \Pi_{C} \frac{\hat{g}_{c}}{g_{c}\left(g_{c}-\hat{g}_{c}\right)} .
$$

In objective (25), the two new terms compute the cost associated with the $\eta$ worst-case-impact values of $r_{j c d}$. The robust optimization formulation includes the previously presented constraints (2) through (24), along with new constraints (26) and (27) which identify these $\eta$ worst-caseimpact values of $r_{j c d}$. As an example, if we assume a protection level of $\eta=2$, $s$ will equal the second-largest potential cost deviation value $b_{c} r_{j c d}$ based on the selected values of all decision variables. Variable $t_{j c d}$ will equal the maximum of zero and the difference between any individual deviation $b_{c} r_{j c d}$ based and the second-largest value $s$. 
4.3. Computational Results. The robust optimization model presented above was coded in GAMS version 24.3.3 and solved using CPLEX version 12.6.0.1. Recall that the input parameter $\eta$ determines how risk-averse the model's solution will be. We will illustrate our solution methodology by considering two values for this parameter: $\eta=0$ (referred to as the nonrobust solution) which is optimized without accounting for any data parameter uncertainty and $\eta=100$ (referred to as the highly robust solution) for which our model identifies the minimum-cost solution in the event that the 100 worstimpacting data parameter uncertainties take their worst-case values (i.e., the 100 largest $b_{c} r_{j c d}$ values are added to the objective function). Figures 4 and 5 show the distribution of receptacles around the MU campus for these two different optimization solutions.

As we select solutions that are more protected from the impact of data uncertainty, we can observe from Figures 4 and 5 that the number of waste collection points increases, from 15 points for the nonrobust solution to 27 points for the highly robust solution. Also, the types of receptacles utilized changes, with the nonrobust solution using compactors at three waste collection points, while the highly robust solutions utilizes no compactors. Neither solution, however, uses any of the small 2-cubic yard dumpsters which are prevalent in MU's current posture (as indicated in Figure 1).

Each solution consists of a set of decisions (receptacle types, locations, and service frequencies; assignment of waste generation points to waste collection points) that are made at the conclusion of planning and then fixed for execution. For any solution, at the start of execution, we do not know how many uncertain data parameters will take a value different from their midpoint estimate. In order to compare the costs of these solutions, we need to consider a common uncertainty scenario for each solution; let $\hat{\eta}$ denote the number of data parameters that are permitted to take their worst-impact values, given a fixed solution. Figure 6 presents the total cost for the current system, along with the cost of both the nonrobust solution and the highly robust solution, across a range of $\hat{\eta}$ data parameter uncertainty levels. At the bestcase outcome for data parameter uncertainty, the nonrobust solution would be slightly less expensive than the highly robust solution (total annual costs of $\$ 276,038$ and $\$ 282,236$, resp.), both of which are considerably less expensive than the current solution of $\$ 410,106$ (both reduce costs by greater than 30 percent under this scenario). However, if just one of the uncertain data parameters is allowed to take its worstimpact value $(\hat{\eta}=1)$, the nonrobust solution would be considerably more expensive than the highly robust solution (total annual costs of $\$ 296,619$ and $\$ 282,839$ ). The difference between the two solutions becomes more pronounced as the values of $\hat{\eta}$ increase, until at the point $\widehat{\eta}=46$ (i.e., the 46 worst-impact data variations occur), the nonrobust solution's cost has increased to its worst-possible value of \$511,426 (an 85 percent increase over this solution's best-case cost should no data variability occur); beyond this $\hat{\eta}$ value the objective does not increase further. The highly robust solution's cost increases with $\hat{\eta}$ until the point $\hat{\eta}=11$, where this solution's objective has increased to its worst-possible value of $\$ 284,818$ (a 0.9 percent increase over this solution's best-case cost, if no data variation occurs). Clearly, the highly robust solution, while slightly more expensive than the nonrobust solution in the most-optimistic future $(\widehat{\eta}=0)$, significantly outperforms the nonrobust solution for all other potential futures (values of $\hat{\eta}>0)$.

Recall our earlier assumption that the transportation of waste between generation points and collection points is not performed by the city of Columbia and thus not included in the university's bill. Should transportation be needed between waste generation and collection points, university custodial staff would need to perform these movements. In discussions with university management, they viewed the current custodial staff manpower as being sufficient to handle this new transportation workload (in fact, some such movement of waste between buildings already occurs at the university). While the university was not able to provide us with an estimate of the costs associated with such movements, we know that this could constitute a new workload for university staff. Accordingly, we generated another set of solutions using our robust optimization model, this time adding a new constraint: a waste generation point can only assign its waste to collection points located within a 0.25 mile radius. Figures 7 and 8 show the distribution of receptacles around the MU campus for the nonrobust $(\eta=0)$ and highly robust $(\eta=$ $100)$ solutions, applying this 0.25 -mile maximum distance constraint.

As expected, when a constraint is added limiting the maximum distance that waste can be transported between generation and collection points, the number of collection points increases. We again observe in Figures 7 and 8 that when we select solutions that are more protected from the impact of data uncertainty, the number of waste collection points increases, from 28 points for the nonrobust solution to 37 points for the highly robust solution. Each of these solutions uses a mix of receptacle types, with each using compactors at some points and small 2-cubic yard dumpsters at other points.

Figure 9 presents the associated cost of both the nonrobust solution and the highly robust solution, across a range of $\hat{\eta}$ data parameter uncertainty levels, when a maximum distance of 0.25 miles is allowed between any waste generation point and its assigned collection point. At the bestcase outcome for data parameter uncertainty, the nonrobust solution would be slightly less expensive than the highly robust solution (total annual costs of $\$ 283,455$ and $\$ 291,465$, resp.). These costs represent increases of 2.7 and 3.3 percent, respectively, over the best-case costs achieved when no such maximum distance constraint was included. When a maximum distance constraint is included, the difference between the nonrobust and highly robust solutions' performance relative to their respective worst-case scenarios was much greater, with the nonrobust solution's cost increasing to $\$ 504,954$ at the point $\hat{\eta}=69$ (i.e., the 69 worst-impact data variations occur), constituting a 78 percent increase over this solution's best-case cost; beyond this $\hat{\eta}$ value the objective does not increase further. The highly robust solution's cost increases with $\hat{\eta}$ until the point $\hat{\eta}=28$, where this solution's objective has increased to its worst-possible value of $\$ 427,243$ (a 47 percent increase over this solution's best-case cost should no 

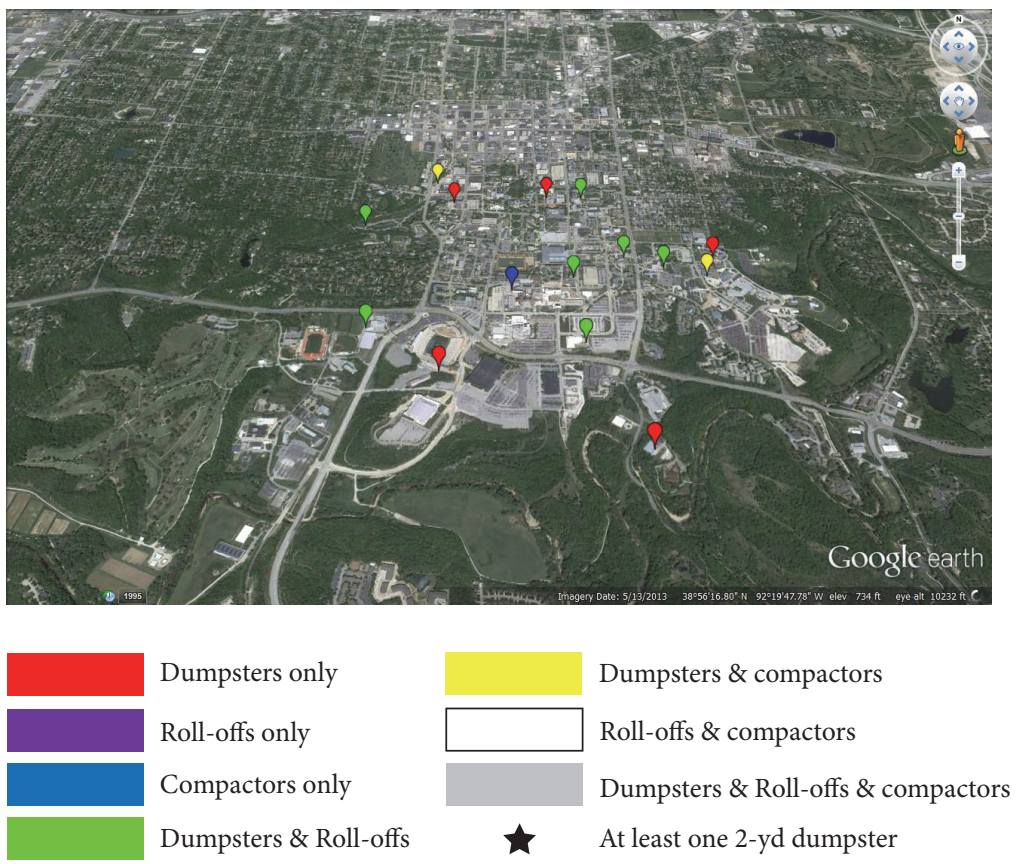

FIGURE 4: Distribution of receptacles around MU campus, nonrobust $(\eta=0)$ solution.
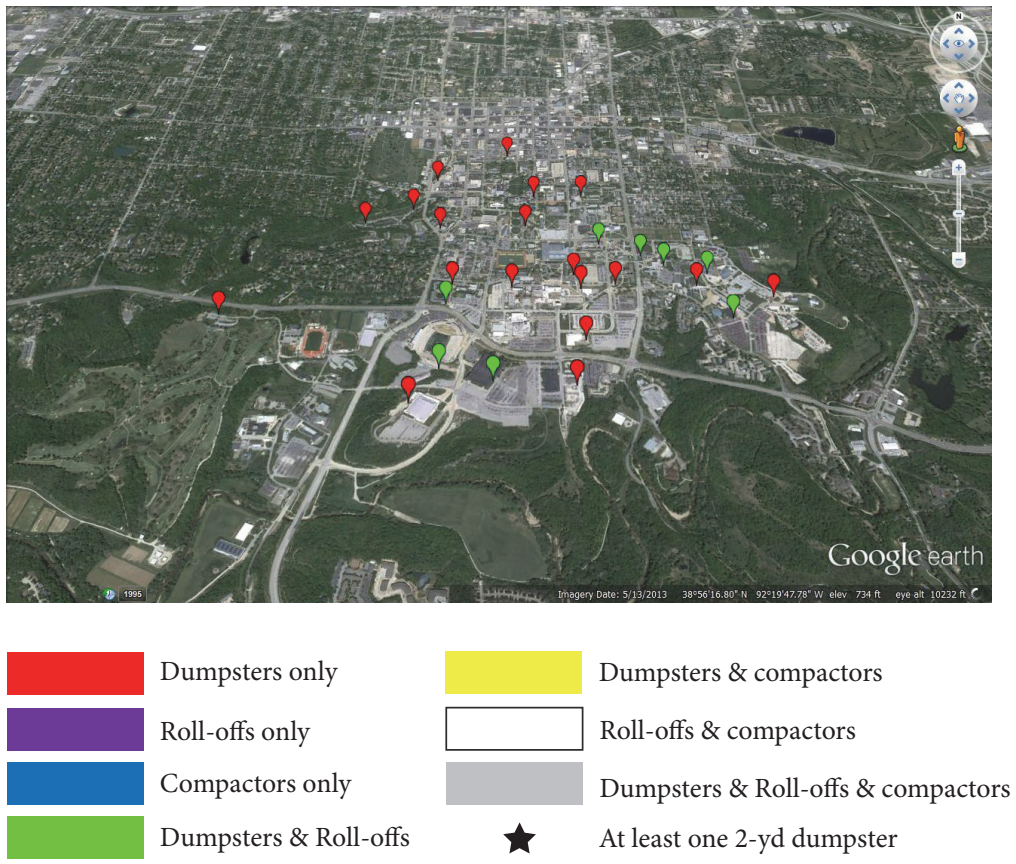

FIGURE 5: Distribution of receptacles around MU campus, highly robust $(\eta=100)$ solution.

data variation occurs). Here, the highly robust solution, while slightly more expensive than the nonrobust solution in the six most-optimistic future $(\widehat{\eta} \leq 5)$, outperforms the nonrobust solution for all other potential futures (all values of $\hat{\eta}>5$ ).

Observe that when a maximum distance of 0.25 miles is allowed between any waste generation point and its assigned collection point, the highly robust solution has a worst-case outcome cost of $\$ 427,243$. This occurs because, under this maximum distance constraint, the highest demand location (University Hospital and Clinics) must be serviced by an on-site compactor, and the worst-case variability associated with this compactor is extremely large (accounting for all of the cost increase between $\hat{\eta}=0$ and $\hat{\eta}=5$ in Figure 9). The $\$ 410,106$ value presented as the current system's cost was calculated as a conservatively low estimate, assuming that all compactors and roll-offs would only be serviced when filled 


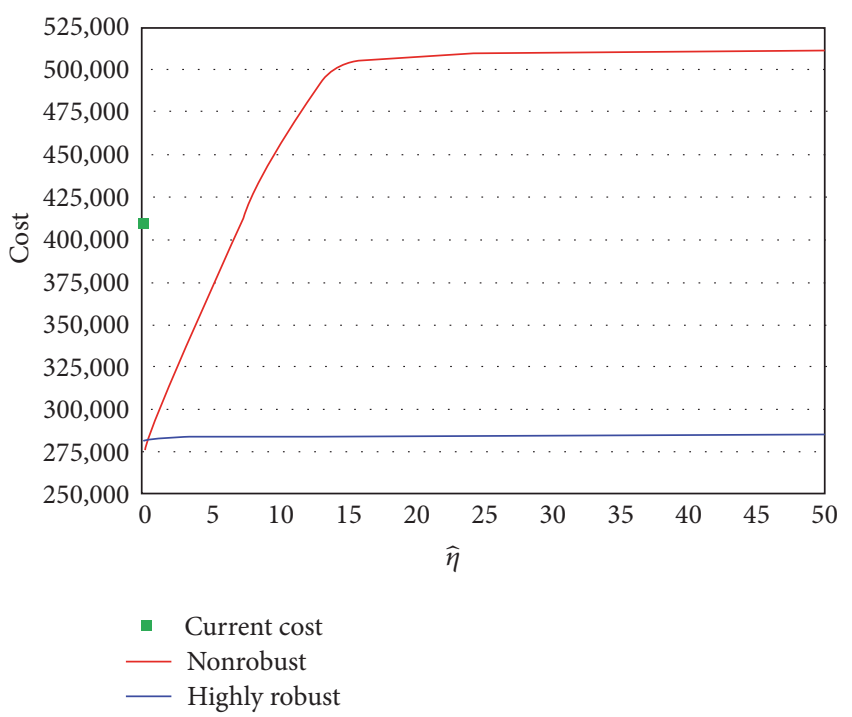

FIGURE 6: Range of potential cost values for nonrobust and highly robust solutions.

to capacity (thereby generating a relatively low estimate for the cost of the current system, in order to not overstate the potential for cost reductions). However, since the current contract has a compactor at the University Hospital and Clinics site, it would be equally susceptible to potential cost increases (over its $\$ 410,106$ baseline) if variability occurs in compactor pull weight at this site.

4.4. Further Computational Testing. In order to develop a greater understanding of the impact of the model parameters on the solutions, a set of 80 additional problem instances was generated and solved. These instances were created by generating a full factorial design that varied five parameters across the following levels:

(i) $\theta_{u f}$ : baseline values and $2 x$ baseline values (2 levels).

(ii) $\Pi_{C}$ : baseline values and $2 x$ baseline values ( 2 levels).

(iii) $\Psi: 10,15,20,25$, and 30 cubic yards per ton of waste (5 levels).

(iv) $\eta: 0$ and 100 (2 levels).

(v) Maximum transport distance: unconstrained and 0.25 miles ( 2 levels).

All instances were run on the computer described in the previous section. In no instance was GAMS/CPLEX able to identify an optimal solution within a 4-hour maximum run time. The results of these additional computational tests are presented in Tables 3 and 4 . The values in each cell present details of the solutions, for each model run: number of collection points, total number of dumpsters, total number of roll-offs, and total number of compactors.

Observe that as $\theta_{u f}$ is increased, the number of collection points and the total number of dumpsters utilized decreases. The effect is much more pronounced for the case with maximum transport distance of 0.25 miles. This is partially due to the two instances in Table 3 for which CPLEX/GAMS was not able to improve the initial solution with collection at all 111 sites; extending the computational run time for these two instances would generate an improved solution. Conversely, as $\Pi_{C}$ is increased, when $\theta_{u f}$ remains at its baseline level, the number of dumpsters increases. However, when both $\Pi_{C}$ and $\theta_{u f}$ are increased, the number of dumpsters generally decreases. As $\Psi$ increases, the number of dumpsters generally decreases and the number of roll-offs increases. As observed in the previous section, increasing the robustness level significantly increases the number of collection points and dumpsters; it also leads to a significantly increased number of compactors for the case with unconstrained maximum transport distance. Similarly, as observed in the previous section, decreasing the maximum-allowable transport distance slightly increases the number of collection points, considerably increases the number of dumpsters and roll-offs, but reduces the number of compactors.

\section{Conclusions and Suggestions for Future Research}

In this paper, we considered the problem faced by a purchaser of SWM services. The purchaser needs to identify the locations at which waste will be collected. Two types of receptacles can be used: one (dumpsters) for which the purchaser identifies a collection schedule in advance and pays a fixed fee according to the number of times the dumpster is serviced (emptied) each week; the other (compactors) for which there is no predetermined servicing schedule, with the purchaser paying a fee comprised of a fixed service charge, plus a variable cost that is assessed on a per-ton-removed basis. Thus, the purchaser also needs to determine the type and number of receptacles to be placed at each waste collection point and the frequency of service (emptying) for dumpster-type receptacles. A final set of decisions facing the purchaser is the assignment of waste generation points (assumed here to be buildings) to waste collection points. Any transportation necessary between waste generation and waste collection points is performed by the SWM purchaser and is not a responsibility of the waste management provider.

We assume that the purchaser wishes to minimize the costs paid to the waste management provider, subject to a level of service that is sufficient to collect all of the purchaser's required waste. We further assume that the amount of waste generated on each day at each waste generation point is known. A mathematical model was presented to determine the minimum-cost strategy for such a purchaser. The primary novel aspect to this model appears in the constraints relating scheduled frequency of service to capacity for dumpsters. We need to relate the day that dumpster-serviced waste is generated to the first-scheduled service date following generation, to ensure that capacity is not violated on any day.

This study was motivated by the situation facing the University of Missouri as it structures its municipal solid waste management contract with the city of Columbia, MO, to collect waste around campus. Examining historical data, we observed significant variability in the amount of waste contained in compactors per pull. Because this variability has a significant impact on the total cost, due to the per-service 

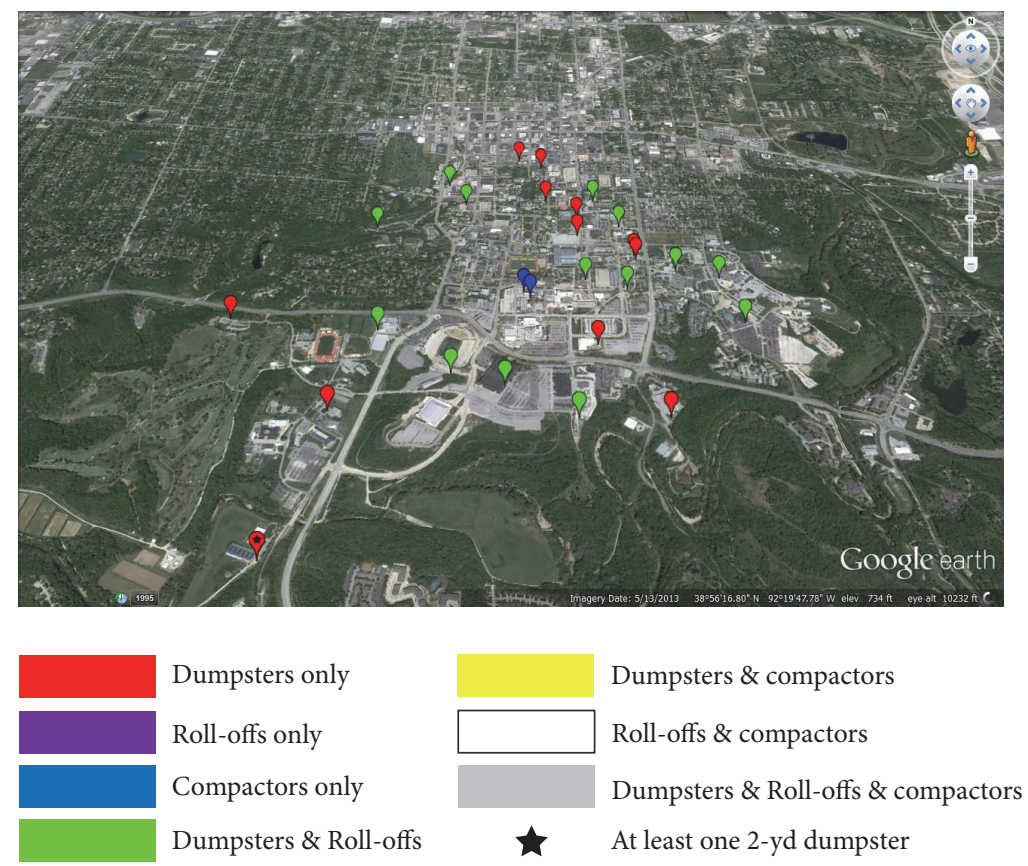

FIGURE 7: Distribution of receptacles around MU campus, nonrobust $(\eta=0)$ solution, maximum transport distance of 0.25 miles.
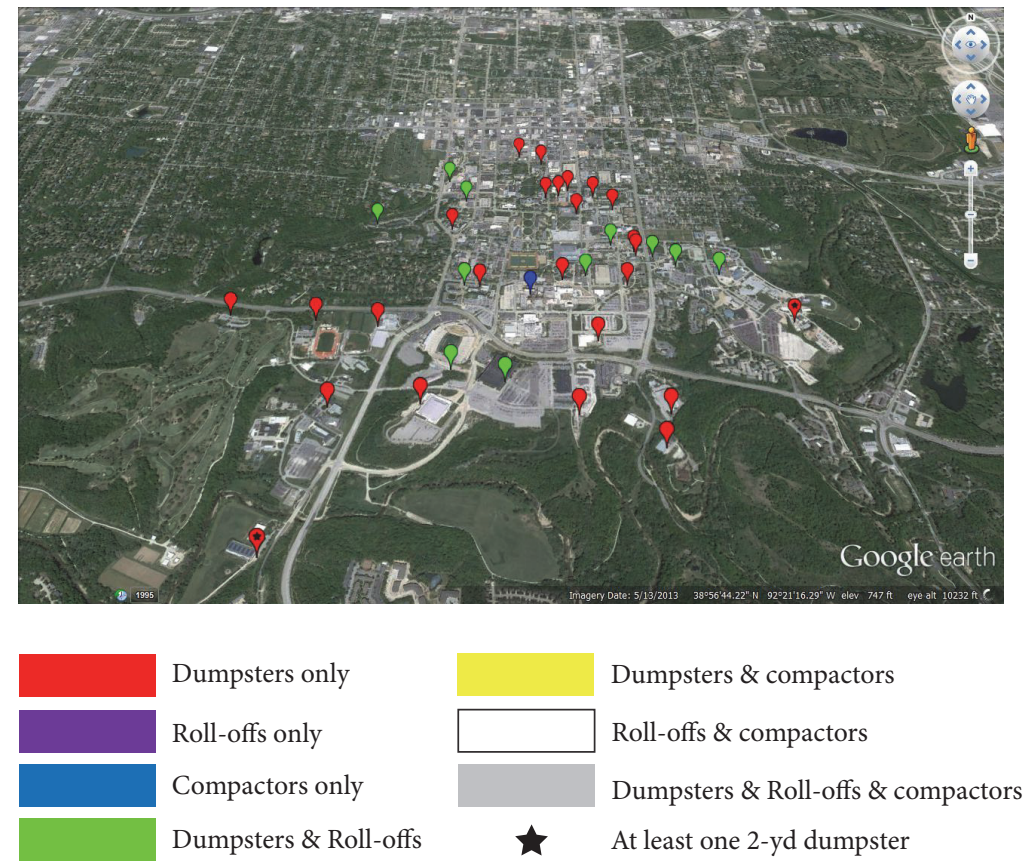

FIGURE 8: Distribution of receptacles around MU campus, highly robust $(\eta=100)$ solution, maximum transport distance of 0.25 miles.

pull fees associated with compactors, we modified our model using robust optimization techniques to address the level of observed uncertainty.

We solved the model with different parameter settings to identify both a nonrobust and a highly robust solution. The primary differences between these two solutions were the increased number of waste collection locations utilized in the highly robust solution and the highly robust solution's lack of usage of compactors. Both solutions would potentially reduce costs significantly, when compared to our estimate of the university's current cost. At the best-case outcome for data parameter uncertainty, the nonrobust solution would be slightly less expensive than the highly robust solution, but either solution would reduce costs by greater than 30 percent under this scenario. However, under the worst-case scenario (in which an unlimited number of data variations are allowed 
TABLE 3: Further computational results, unconstrained maximum transport distance.

\begin{tabular}{|c|c|c|c|c|c|c|c|}
\hline & & $\Psi=10$ & $\Psi=15$ & $\Psi=20$ & $\Psi=25$ & $\Psi=30$ & Averages \\
\hline$\theta_{u f}:$ baseline & $\eta=0$ & $31,26,0,10$ & $32,17,0,18$ & $22,14,0,12$ & $22,8,0,15$ & $17,3,5,11$ & $24.8,13.6,1.0,13.2$ \\
\hline$\Pi_{C}:$ baseline & $\eta=100$ & $86,62,0,28$ & $70,45,0,29$ & $71,46,0,29$ & $51,37,6,22$ & $58,33,0,29$ & $67.2,44.6,1.2,27.4$ \\
\hline$\theta_{u f}:$ baseline & $\eta=0$ & $58,62,3,7$ & $36,36,6,6$ & $33,21,6,11$ & $26,29,3,9$ & $23,13,1,12$ & $35.2,32.2,3.8,9.0$ \\
\hline$\Pi_{C}: 2 \mathrm{x}$ baseline & $\eta=100$ & $89,66,0,27$ & $88,64,0,28$ & $84,61,0,27$ & $78,54,0,28$ & $75,51,0,28$ & $82.8,59.2,0.0,27.6$ \\
\hline$\theta_{u f}: 2 \mathrm{x}$ baseline & $\eta=0$ & $111,86,0,28$ & $111,86,0,28$ & $17,3,4,10$ & $21,5,0,17$ & $17,2,3,12$ & $55.4,36.4,1.4,19.0$ \\
\hline$\Pi_{C}:$ baseline & $\eta=100$ & $43,18,0,29$ & $37,11,0,29$ & $35,9,0,29$ & $35,9,0,29$ & $34,8,0,29$ & $36.8,11.0,0.0,29.0$ \\
\hline$\theta_{u f}: 2 \mathrm{x}$ baseline & $\eta=0$ & $20,14,0,11$ & $13,0,5,9$ & $25,4,1,20$ & $17,1,3,15$ & $17,1,5,14$ & $18.4,4.0,2.8,13.8$ \\
\hline$\Pi_{C}: 2 \mathrm{x}$ baseline & $\eta=100$ & $39,14,0,28$ & $41,16,0,28$ & $40,15,0,28$ & $38,12,0,29$ & $37,11,0,29$ & $39.0,13.6,0.0,28.4$ \\
\hline Averages & & $\begin{array}{c}59.6,43.5 \\
0.4,21.0\end{array}$ & $\begin{array}{c}53.5,34.4 \\
1.4,21.9\end{array}$ & $\begin{array}{c}40.9,21.6 \\
1.4,20.8\end{array}$ & $\begin{array}{c}36.0,19.4 \\
1.5,20.5\end{array}$ & $\begin{array}{c}34.8,15.3 \\
1.8,20.5\end{array}$ & $45.0,26.8,1.3,20.9$ \\
\hline
\end{tabular}

TABLE 4: Further computational results, maximum transport distance of 0.25 miles.

\begin{tabular}{|c|c|c|c|c|c|c|c|}
\hline & & $\Psi=10$ & $\Psi=15$ & $\Psi=20$ & $\Psi=25$ & $\Psi=30$ & Averages \\
\hline$\theta_{u f}:$ baseline & $\eta=0$ & $54,63,1,15$ & $37,48,2,15$ & $30,31,3,14$ & $33,28,2,15$ & $26,12,2,13$ & $36.0,36.4,2.0,14.4$ \\
\hline$\Pi_{C}$ : baseline & $\eta=100$ & $63,70,3,12$ & $57,67,1,12$ & $68,67,3,21$ & $56,69,3,13$ & $54,49,3,21$ & $59.6,64.4,2.6,15.8$ \\
\hline$\theta_{u f}:$ baseline & $\eta=0$ & $64,77,0,14$ & $51,72,0,12$ & $54,61,2,15$ & $44,54,2,14$ & $30,33,4,11$ & $48.6,59.4,1.6,13.2$ \\
\hline$\Pi_{C}: 2 \mathrm{x}$ baseline & $\eta=100$ & $72,86,2,13$ & $73,78,4,17$ & $76,88,1,17$ & $59,67,3,14$ & $56,67,3,11$ & $67.2,77.2,2.6,14.4$ \\
\hline$\theta_{u f}: 2 \mathrm{x}$ baseline & $\eta=0$ & $31,18,2,18$ & $38,33,0,20$ & $35,26,2,16$ & $41,38,2,15$ & $23,24,2,14$ & $33.6,27.8,1.6,16.6$ \\
\hline$\Pi_{C}:$ baseline & $\eta=100$ & $52,57,3,17$ & $50,39,7,20$ & $38,22,3,22$ & $59,45,5,20$ & $59,44,6,20$ & $51.6,41.4,4.8,19.8$ \\
\hline$\theta_{u f}: 2 \mathrm{x}$ baseline & $\eta=0$ & $31,34,1,16$ & $24,7,1,16$ & $20,8,5,9$ & $25,14,5,14$ & $34,18,3,16$ & $26.8,16.2,3.0,14.2$ \\
\hline$\Pi_{C}: 2 \mathrm{x}$ baseline & $\eta=100$ & $52,49,5,19$ & $57,57,1,18$ & $48,37,7,20$ & $48,41,2,22$ & $45,34,2,23$ & $50.0,43.6,3.4,20.4$ \\
\hline Averages & & $\begin{array}{c}52.4,56.8 \\
2.1,15.5 \\
\end{array}$ & $\begin{array}{c}48.4,50.1 \\
2.0,16.3\end{array}$ & $\begin{array}{c}46.1,42.5 \\
3.3,16.8\end{array}$ & $\begin{array}{c}45.6,44.5 \\
3.0,15.9\end{array}$ & $\begin{array}{c}40.9,35.1 \\
3.1,16.1\end{array}$ & $46.7,45.8,2.7,16.1$ \\
\hline
\end{tabular}

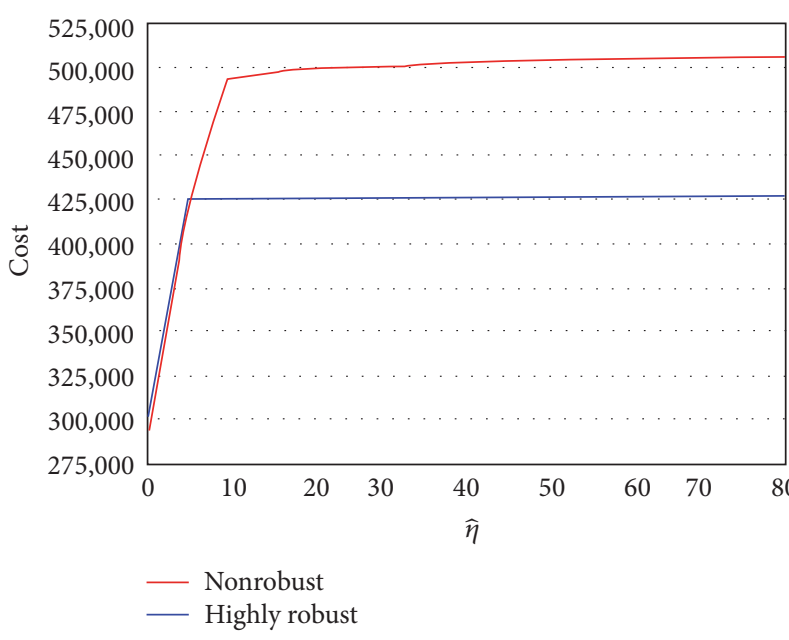

FIGURE 9: Range of potential cost values for nonrobust and highly robust solutions, maximum transport distance of 0.25 miles.

to occur), the nonrobust solution's cost would be liable to an 85 percent increase over this solution's best-case cost, whereas the highly robust solution's cost would be subject to only a 0.9 percent increase over this solution's best-case cost. Clearly, the highly robust solution, while slightly more expensive than the nonrobust solution in the most-optimistic future, significantly outperforms the nonrobust solution for all other potential futures.

Because we assumed that the transportation of waste between generation points and collection points is not included in the purchaser's SWM bill (based on our conversations with MU, who viewed the current custodial staff manpower as being sufficient to handle this new transportation workload), we included no mechanism in our first set of model results to constrain this transportation. To examine the impacts of adding such considerations, we generated another set of solutions using our robust optimization model, this time adding a new constraint: a waste generation point can only assign its waste to collection points located within a 0.25 mile radius, again identifying a nonrobust and a highly robust solution.

As expected, when a constraint is added limiting the maximum distance that waste can be transported between generation and collection points, the number of collection points increases. Both the nonrobust and highly robust solutions use a mix of receptacle types, with each using compactors at some points and small 2-cubic-yard dumpsters at other points, due to the maximum distance constraint.

At the best-case outcome for data parameter uncertainty, the nonrobust solution would be slightly less expensive than the highly robust solution. Both solutions would be subject to a cost increase of roughly three percent, relative to the best-case costs achieved when no such maximum distance 
constraint was included. However, the difference for the maximum-distance-constrained solutions relative to their respective worst-case scenarios is much greater, with the nonrobust solution's cost increasing by 78 percent over this solution's best-case cost and the highly robust solution's cost increasing by 47 percent over this solution's best-case cost. The highly robust solution is potentially subject to such large cost increases, under this maximum distance constraint, the highest demand location (University Hospital and Clinics) must be serviced by an on-site compactor, and the worst-case variability associated with this compactor is extremely large (accounting for nearly all of the potential cost increase). These results suggest that solid waste planning, which up to now has typically implemented deterministic optimizations that do not account for uncertainty, can produce recommendations that do not perform well in the event of uncertainty and that such planning can be considerably improved across a range of potential futures by the use of robust optimization models.

A number of future research directions can be envisioned. First, the transportation of waste between buildings is not included as a cost in this formulation (due to the belief on the part of university management that their existing resources are sufficient to handle this additional workload). However, where it possible to identify a cost structure for this transportation, one could integrate these costs into our model's objective function. Second, it is unlikely that a deterministic amount of waste is generated on campus each day. Where it possible to collect data regarding this uncertainty in the volume of waste generated each day at each building, this uncertainty could be incorporated into the robust optimization model, potentially yielding an improved solution.

\section{Disclosure}

The present address for Maryam Nikouei Mehr is Department of Industrial and Manufacturing Systems Engineering, Iowa State University, Ames, IA 50011.

\section{Competing Interests}

The authors declare that there is no conflict of interests regarding the publication of this paper.

\section{Acknowledgments}

The authors would like to thank the University of Missouri's Sustainability Office for providing the data that was utilized in the case study application, which was performed as part of the first author's thesis [32] while she was a graduate student at the University of Missouri.

\section{References}

[1] G. Tchobanoglous, H. Theisen, and S. Vigil, Integrated Solid Waste Management: Engineering Principles and Management Issues, McGraw-Hill, New York, NY, USA, 1993.

[2] United Nations, Glossary of Environment Statistics, Studies and Methods, Series F, No. 67, United Nations, New York, NY, USA, 1997.
[3] E. Shamshiry, B. Nadi, and A. R. Mahmud, "Optimization of municipal solid waste management," in Proceedings of the International Conference on Biology, Environment and Chemistry, vol. 1, pp. 119-121, 2011.

[4] A. J. Morrissey and J. Browne, "Waste management models and their application to sustainable waste management," Waste Management, vol. 24, no. 3, pp. 297-308, 2004.

[5] M. F. Badran and S. M. El-Haggar, "Optimization of municipal solid waste management in Port Said-Egypt," Waste Management, vol. 26, no. 5, pp. 534-545, 2006.

[6] G. Ghiani, D. Laganà, E. Manni, and C. Triki, "Capacitated location of collection sites in an urban waste management system," Waste Management, vol. 32, no. 7, pp. 1291-1296, 2012.

[7] A. P. Antunes, "Location analysis helps manage solid waste in Central Portugal," Interfaces, vol. 29, no. 4, pp. 32-43, 1999.

[8] A. P. Antunes, J. C. Teixeira, and M. S. Coutinho, "Managing solid waste through discrete location analysis: A Case Study In Central Portugal," Journal of the Operational Research Society, vol. 59, no. 8, pp. 1038-1046, 2008.

[9] H. A. Eiselt, "Locating landfills-optimization vs. reality," European Journal of Operational Research, vol. 179, no. 3, pp. 10401049, 2007.

[10] E. Erkut, A. Karagiannidis, G. Perkoulidis, and S. A. Tjandra, "A multicriteria facility location model for municipal solid waste management in North Greece," European Journal of Operational Research, vol. 187, no. 3, pp. 1402-1421, 2008.

[11] G. Galante, G. Aiello, M. Enea, and E. Panascia, "A multi-objective approach to solid waste management," Waste Management, vol. 30, no. 8-9, pp. 1720-1728, 2010.

[12] L. Jenkins, "Parametric mixed integer programming: an application to solid waste management," Management Science, vol. 28, no. 11, pp. 1270-1284, 1982.

[13] B. W. Baetz, E. I. Pas, and A. W. Neebe, "Trash management: sizing and timing decisions for incineration and landfill facilities," Interfaces, vol. 19, no. 6, pp. 52-61, 1989.

[14] C. Berger, G. Savard, and A. Wizere, "EUGENE: an optimization-based decision support system for long-term integrated regional waste management planning," International Journal of Environment and Pollution, pp. 437-449, 1998.

[15] P. Fiorucci, R. Minciardi, M. Robba, and R. Sacile, "Solid waste management in urban areas: development and application of a decision support system," Resources, Conservation and Recycling, vol. 37, no. 4, pp. 301-328, 2003.

[16] B. Noche, F. A. Rhoma, T. Chinakupt, and M. Jawale, "Optimization model for solid waste management system network design case study," in Proceedings of the 2nd International Conference on Computer and Automation Engineering (ICCAE '10), pp. 230236, February 2010.

[17] G. Ghiani, D. Laganà, E. Manni, R. Musmanno, and D. Vigo, "Operations research in solid waste management: a survey of strategic and tactical issues," Computers \& Operations Research, vol. 44, pp. 22-32, 2014.

[18] G. Ghiani, A. Manni, E. Manni, and M. Toraldo, "The impact of an efficient collection sites location on the zoning phase in municipal solid waste management," Waste Management, vol. 34, no. 11, pp. 1949-1956, 2014.

[19] M. K. Ghose, A. K. Dikshit, and S. K. Sharma, "A GIS based transportation model for solid waste disposal - a case study on Asansol municipality," Waste Management, vol. 26, no. 11, pp. 1287-1293, 2006. 
[20] S. Hanafi, A. Freville, and P. Vaca, "Municipal solid waste collection: an effective data structure for solving the sectorization problem with local search methods," INFOR Journal, vol. 37, pp. 236-254, 1999.

[21] K. Katragjini, F. Perea, and R. Ruiz, "Efficient waste collection by means of assignment problems," in Proceedings of the 1st International Conference on Operations Research and Enterprise Systems (ICORES '12), pp. 283-292, Setúbal, Portugal, February 2012.

[22] G. H. Huang, B. W. Baetz, and G. G. Patry, "A grey fuzzy linear programming approach for municipal solid waste management planning under uncertainty," Civil Engineering Systems, vol. 10, no. 2, pp. 123-146, 1993.

[23] Y. F. Huang, B. W. Baetz, G. H. Huang, and L. Liu, "Violation analysis for solid waste management systems: an interval fuzzy programming approach," Journal of Environmental Management, vol. 65, no. 4, pp. 431-446, 2002.

[24] Y. P. Li, G. H. Huang, X. H. Nie, and S. L. Nie, "A two-stage fuzzy robust integer programming approach for capacity planning of environmental management systems," European Journal of Operational Research, vol. 189, no. 2, pp. 399-420, 2008.

[25] M. M. Sobral, K. W. Hipel, and G. J. Fargugar, "Multi-criteria model for solid waste management," Journal of Environmental Management, vol. 12, no. 2, pp. 97-110, 1981.

[26] Q. Tan, G. H. Huang, and Y. P. Cai, "Waste management with recourse: an inexact dynamic programming model containing fuzzy boundary intervals in objectives and constraints," Journal of Environmental Management, vol. 91, no. 9, pp. 1898-1913, 2010.

[27] Y. Li, Development of an inexact two-stage mixed integer linear programming method for solid waste management under uncertainty [M.S. thesis], Environmental System Engineering, University of Regina, Regina, Canada, 2004.

[28] A. Ben-Tal and A. Nemirovski, "Robust solutions of uncertain linear programs," Operations Research Letters, vol. 25, no. 1, pp. $1-13,1999$.

[29] J. A. Rappold and B. D. Van Roo, "Designing multi-echelon service parts networks with finite repair capacity," European Journal of Operational Research, vol. 199, no. 3, pp. 781-792, 2009.

[30] D. Bertsimas and M. Sim, "Robust discrete optimization and network flows," Mathematical Programming, vol. 98, no. 1-3, pp. 49-71, 2003.

[31] V. Gabrel, C. Murat, and A. Thiele, "Recent advances in robust optimization: an overview," European Journal of Operational Research, vol. 235, no. 3, pp. 471-483, 2014.

[32] M. Nikouei Mehr, A robust optimization approach to solid waste collection planning: location-allocation, and service frequency [M.S. thesis], Industrial Engineering, University of Missouri, 2014. 


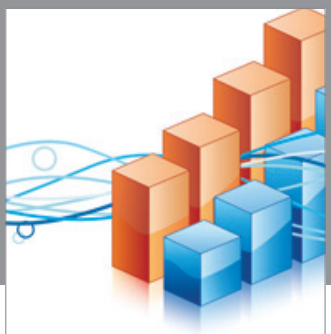

Advances in

Operations Research

vatem alat4

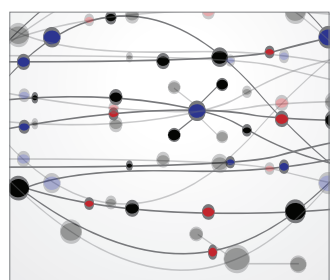

\section{The Scientific} World Journal
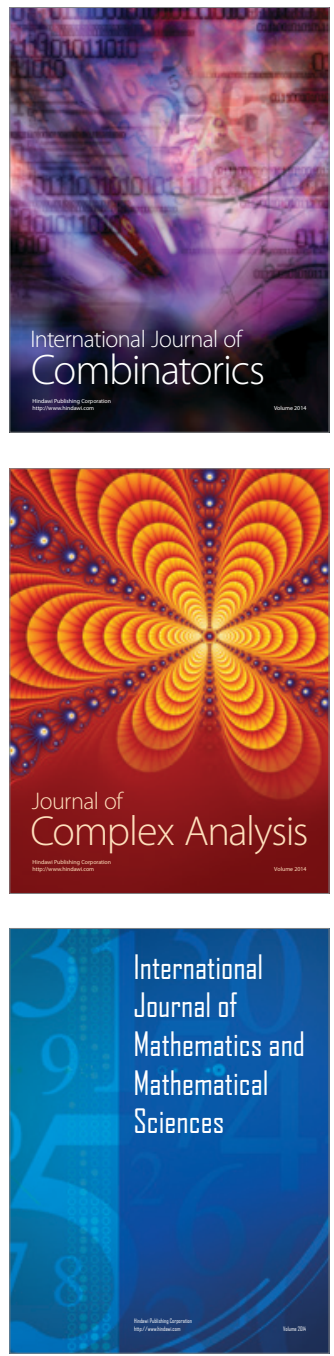
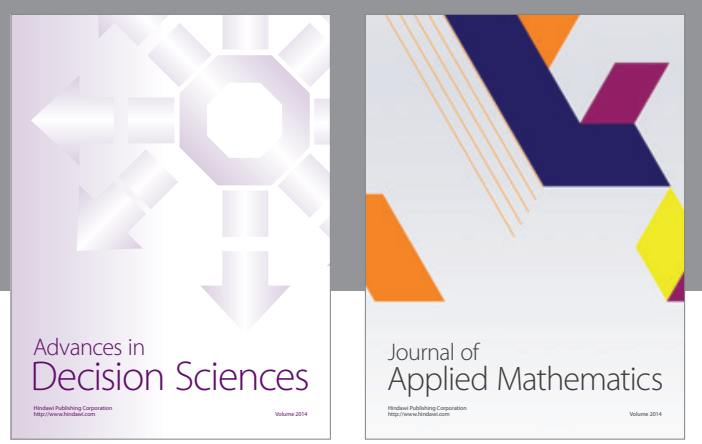

Algebra

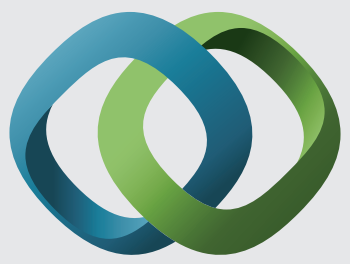

\section{Hindawi}

Submit your manuscripts at

https://www.hindawi.com
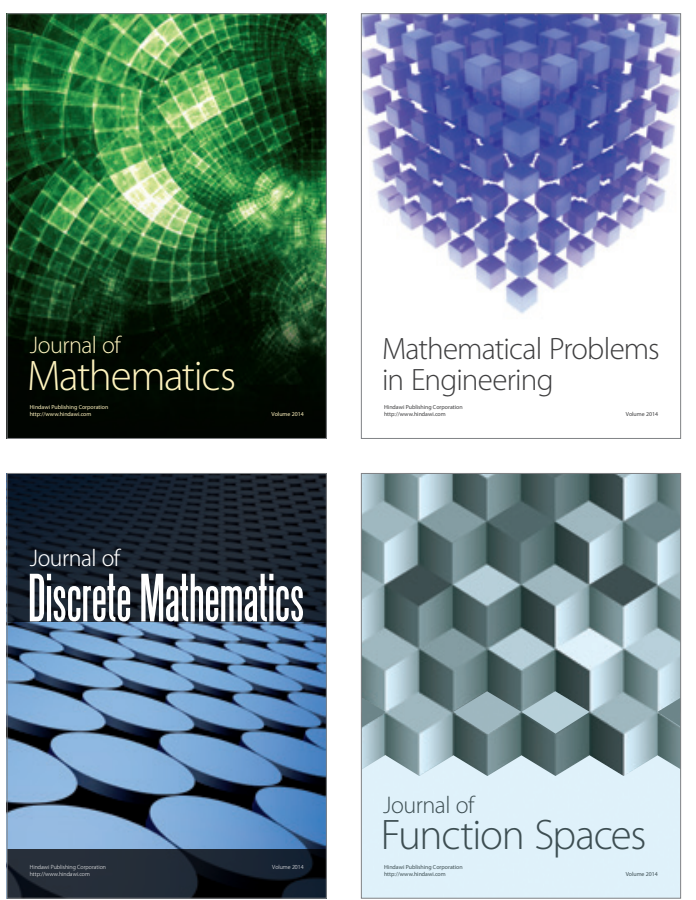

Mathematical Problems in Engineering
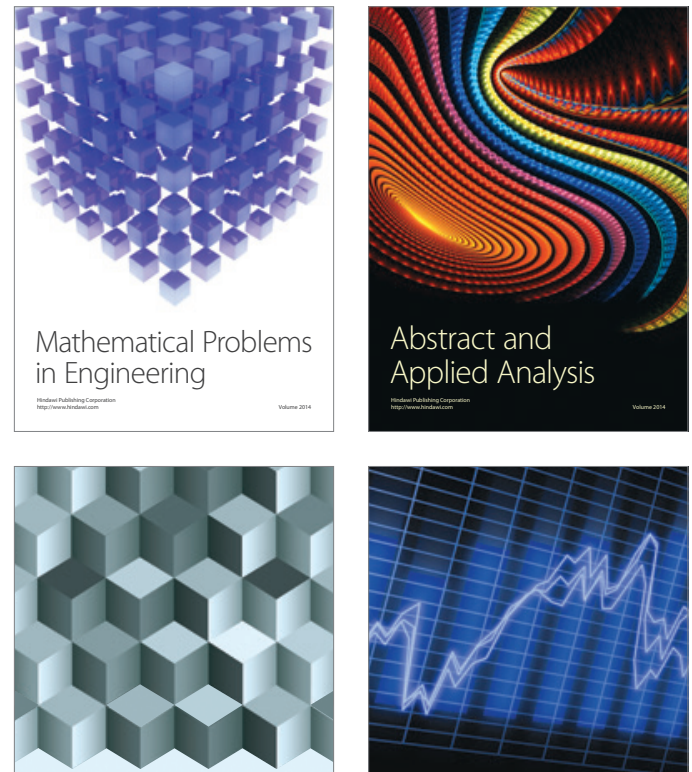

Journal of

Function Spaces

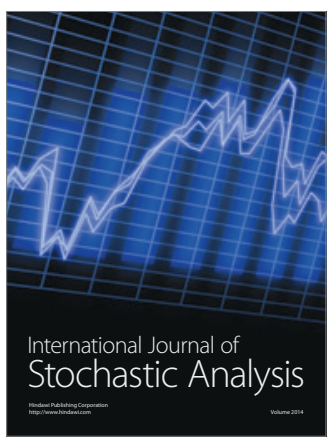

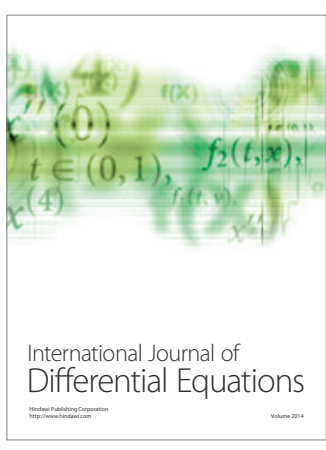
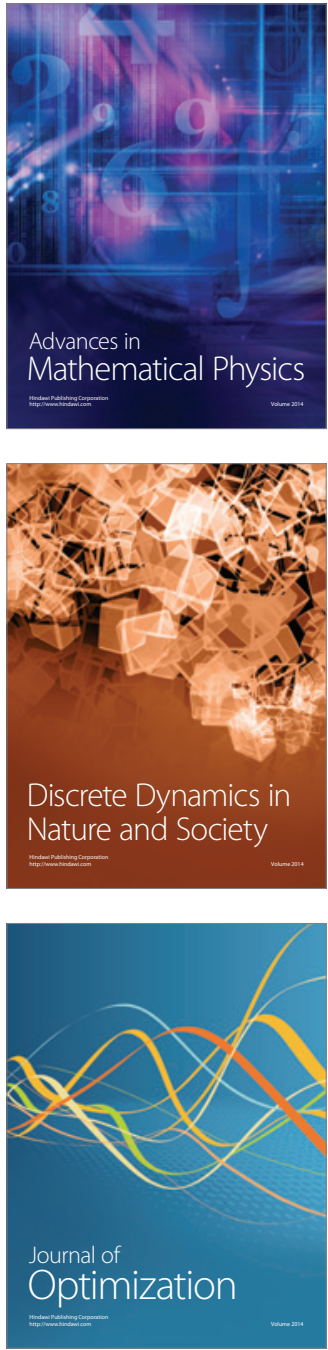